\title{
Letter
}

\section{The Canadian Ice Island Drift, Deterioration and Detection (CI2D3) Database}

\section{INTRODUCTION}

Three recent calving events from the Petermann Glacier, northwest Greenland $\left(80^{\circ} 45^{\prime} \mathrm{N}, 60^{\circ} 45^{\prime} \mathrm{W}\right)$ generated hundreds of individual ice islands that traversed through Nares Strait, Baffin Bay and the Labrador Sea. The calving events of July 2008, August 2010 and July 2012 resulted in the reported loss of 30,253 and $130 \mathrm{~km}^{2}$ from the Petermann Ice Tongue (Münchow and others, 2014). These large, tabular icebergs (as they are referred to in the Antarctic) were observed to drift as far south as Newfoundland, with one example being the April 2012 observation at $42^{\circ} \mathrm{N}$ of a $400 \mathrm{~m}$-long piece that likely originated from the 2010 calving event (Capt. P. Radovan, personal communication). Sometimes smaller pieces generated through fracturing are referred to as ice island fragments (CIS, 2005). We only use the term 'ice islands' for simplicity.

The substantial masses of ice islands make them potential hazards to shipping and offshore oil and gas activities off the East Coast of Canada. They also play a role in the spatial dispersion of fresh water from the Greenland Ice Sheet (Marson and others, 2017) and can be of local importance to marine ecosystems by altering the chemical and physical composition of the water column (Stern and others, 2015) and creating special habitats for phytoplankton, diatoms, bacteria and krill (Vernet and others, 2012; Smith and others, 2013). They can also provide temporary habitat to marine mammals; hundreds of seals were observed on Petermann Ice Island (PII)-A in the southern Labrador Sea in 2011, and seven to ten polar bears were observed on PII-B-1 when it was grounded off the east coast of Baffin Island in 2012 (Halliday and others, 2012; C. Packham, personal communication).

The presence of ice islands in this region tends to be intermittent (Newell, 1993; Johannessen and others, 2011). As a result, their dynamics and physical properties are less well documented than those of the smaller icebergs that drift into Newfoundland waters every year. The recent flux of ice islands from the Petermann Glacier and other northern Greenland glaciers has corresponded with the availability of satellite imagery of suitable temporal frequency, acquisition capability regardless of cloud cover or light conditions (a benefit of synthetic aperture radar (SAR) sensors), and sufficient spatial resolution to identify and monitor ice islands. Collaborators at the Water and Ice Research Laboratory (WIRL) at Carleton University (Ottawa, Canada) and the Canadian Ice Service (CIS; Environment and Climate Change Canada (ECCC), Ottawa, Canada) exploited a large quantity of valuable imagery from the CIS SAR data archive to generate a database of ice island observations. The information contained within the Canadian Ice Island Drift, Deterioration and Detection (CI2D3) Database will be useful in a variety of scientific and engineering studies, and will ultimately lead to a better understanding of these features and the role they play in the ocean environment. Here we provide a description of the unique database's contents and the workflow used to create it. We also demonstrate some of the numerous topics that can be investigated with the database with example analyses. The database will be publically available in the summer of 2018 .

\section{DATA SOURCES AND MONITORED ICE ISLANDS}

The CIS archive primarily contains Level 1b RADARSAT-1 and -2 (R1, R2) C-band SAR data (Canadian Space Agency; MacDonald, Dettwiler and Associates, Ltd.) which were acquired for operational sea ice monitoring in Canadian waters. In-house technicians attempted to represent each ice island originating from the Petermann Glacier, or its immediate descendants, in the database at a minimum 14 d observation interval. However, much smaller intervals (e.g. sub-daily) were often possible based on image availability. Secondary sources of SAR data were collected to meet the minimum interval requirement, if necessary. A small number of ice islands that calved from the Ryder, Steensby and C.H. Ostenfeld ice tongues were also included in the database. These Greenland glaciers are located north of Petermann Glacier and the associated ice islands were monitored only to the extent necessary to ensure that they were not confused with nearby Plls. Further requirements of the database, as well as the specifications and numbers of various products used for its generation, can be obtained through documentation provided on the project's website (www.wirl.carleton.ca/Cl2D3) and Polar Data Catalogue (PDC) entry $\# 12678$.

\section{IMAGE ANALYSIS AND DIGITIZATION METHODS}

\subsection{Database generation workflow}

The CI2D3 Database technicians used GIS software to manually digitize the perimeter of ice islands as polygons. Ice islands can be distinguished in these SAR scenes from ice or open water backgrounds due to their angular shape, large size and high backscatter, the latter of which occurs due to their large fresh water content and possible doublebounce scattering along their edges (Jeffries and others, 1987; De Abreu and others, 2011; Lewis-Paley, 2015). Technicians first identified SAR scenes contained in the CIS archive that fell within a broad region of interest spanning from northwest Greenland to Newfoundland. Using a series of Python/gdal scripts, each image was projected with bilinear resampling to a Lambert Conformal Conic projection (WGS 1984 datum), stretched to improve contrast and saved as geotiff files for subsequent use in ArcGIS (v. 10.2-10.5). The CIS SAR archive predominately includes R1 and R2 ScanSAR Wide scenes with nominal resolutions of $100 \mathrm{~m}$. SAR and optical scenes with 150 and $10 \mathrm{~m}$ resolutions were also acquired by sensors on the Envisat (European Space Agency) and EO-1 (NASA) satellites, respectively. Full details on all utilized satellite imagery can be found in the aforementioned project documentation. 
The polygon associated with the first clear observation of an ice island was digitized from scratch. Subsequent digitization of each ice island was facilitated by copying the original polygon, overlaying it on the subsequent observation and rotating and trimming as needed to optimize the polygon fit. Changes in polygon shape were only made when the technician was confident that the visually observed change was genuine. This ensured that the perceived changes were not misrepresentations of area due to backscatter changes resulting from differences in ice island orientation, beam mode resolution or the look-angle between the satellite and ice island. Ice islands identified in SAR imagery and associated digitized polygons are shown in Figure 1. This manual digitization workflow permitted the technicians to chronicle the ice island lineage (i.e. linking mother to daughter ice islands) for all tracked ice islands down to at least $0.25 \mathrm{~km}^{2}$. Such lineage data was previously only recorded for larger ice islands $(>19 \mathrm{~km}$ in length) tracked by the National Ice Centre in the Antarctic (Tournadre and others, 2016). The arrows in Figure 1

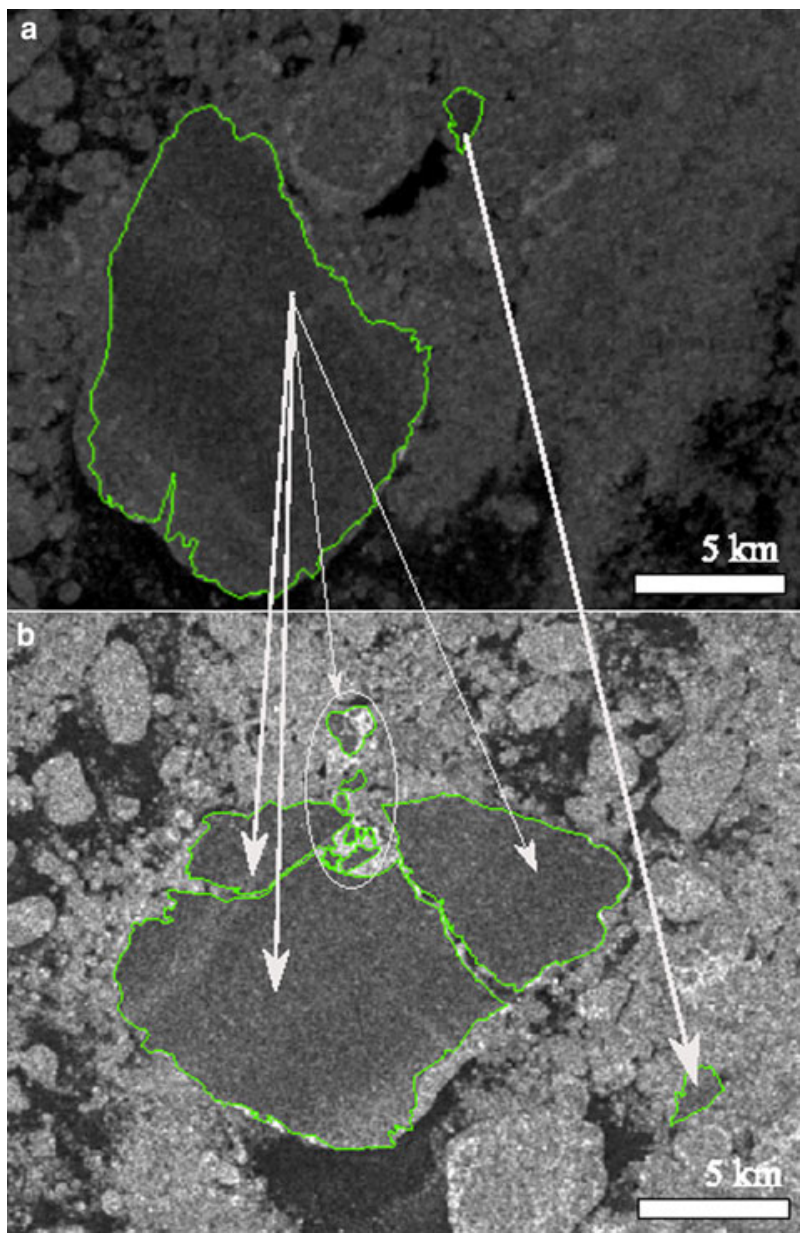

Fig. 1. Example of ice island digitization and lineage connection. Panels (a) and (b) show ice islands identified in (a) ENVISAT ASAR Wide Swath and (b) RADARSAT-2 ScanSAR Wide imagery on 9 October 2010 at 01:55 and 11:55 UTC, respectively. The digitized polygons associated with the identified ice islands are shown in green. Ice islands lineage connections are represented by white arrows. (a) ENVISAT products (c) European Space Agency. RADARSAT-2 Data and Products (c) MacDONALD, DETTWILER AND ASSOCIATES LTD. (2011) - All rights reserved. RADARSAT is an official mark of the Canadian Space Agency. represent the ice island lineage connections that are captured in the database.

Technicians monitored the ice islands, digitized representative polygons and established their lineage using unique identifiers until surface areas reached $<0.25 \mathrm{~km}^{2}$. Ice islands could be reliably identified and digitized above this threshold at the scale used to search imagery (1:250 000) under ideal conditions. A combination of scene resolution, polarization and environmental conditions (i.e. the presence of sea ice, surface meltwater, wind-driven ocean backscatter and/or multiple small fragments) could hinder re-identification. A number of attribute fields were filled for each polygon. All polygons were quality controlled with a series of logic rules coded in SQL language before final upload to a PostgreSQL database. Table 1 includes the number of ice island observations and images associated with each calving event. Digitization is ongoing, but it is expected that the database will extend to December 2013 when the database is made public in summer 2018. An animation of the database's contents can be found in the supplementary material.

\subsection{Error assessment}

An assessment was set up following the work of Paul and others (2013) to capture the uncertainty of the 'polygon trimming' workflow. Four pairs of RADARSAT scenes that captured a particular ice island at different times were chosen to ensure a combination of scene resolutions, polarizations and identification difficulty. Five technicians then followed the workflow described above for each of the four image pairs, trimming each of the four polygons from the first image to best fit the ice island as pictured in the second image. The first digitizations from each technician were compared to derive a percent agreement $(6.2 \%)$ on the ice island area. Each technician repeated four more trials with a minimum 24 hour gap between rounds to determine their internal consistency (mean: $2.5 \%$, range: 1.6-3.4\%). These errors are relevant to $98 \%$ of the current database entries. An analogous 'from scratch' error assessment for the remaining $2 \%$ of the database entries had a between-technician error of $8.4 \%$ and a mean internal-technician error of $5.3 \%$ (range: $3.4-8.6 \%$ ).

\section{PRELIMINARY RESULTS AND DISCUSSION}

Figure 2 shows the locations of all ice island observations recorded to date from the Petermann Glacier calving events of 2008, 2010, 2011 and 2012. The reported areal extents of the initial ice islands have differed in the previous literature due to varying delineation or calculation methods (e.g. pixel counting, calving-front monitoring) and the resolution of utilized satellite imagery (i.e. $250 \mathrm{~m}$ resolution AQUA MODIS (Moderate Resolution Imaging Spectroradiometer; NASA) scenes) (Peterson and others, 2009; Falkner and others, 2011; Johannessen and others, 2011; Münchow and others, 2014). The CI2D3 project utilized higher resolution imagery acquired as closely as possible to the time of calving and measured surface area extents of $30.0 \pm 1.9,292.7 \pm 18.1$ and $136.9 \pm 8.5 \mathrm{~km}^{2}$ for the main ice islands generated from the 2008, 2010 and 2012 calving events, respectively. The representative polygons were also scrutinized against subsequent observations to ensure that the digitized extents were genuine. A number of smaller ice island calving events are 
Table 1. Representation of ice island calving events in the Canadian Ice Island Drift, Deterioration and Detection (CI2D3) Database. The date field refers to the date of the original calving event from the corresponding ice tongue.

\begin{tabular}{|c|c|c|c|c|c|}
\hline Glacier & Date & Total calved ice $\left(\mathrm{km}^{2}\right)$ & Polygons & Images* & Monitoring period \\
\hline Petermann & 10 July 2008 & $36.4 \pm 4.0$ & 332 & 177 & 07/2008-07/2009 \\
\hline Petermann & 5 August 2010 & $302.4 \pm 33.0$ & $8025^{+}$ & $2244^{+}$ & $09 / 2010-12 / 2012^{+}$ \\
\hline Petermann & 16 August and 21 September 2011 & $4.3 \pm 0.42$ & $502^{+}$ & $489^{+}$ & $08 / 2011-10 / 2012^{+}$ \\
\hline Petermann & 17 July 2012 & $144.6 \pm 15.8$ & $1823^{+}$ & $286^{+}$ & $07 / 2012-12 / 2012^{+}$ \\
\hline Ryder $^{\ddagger}$ & - & - & $2345^{+}$ & $185^{+}$ & $08 / 2011-12 / 2012^{+}$ \\
\hline Steensby $^{\ddagger}$ & - & - & $697^{+}$ & $228^{+}$ & $09 / 2011-12 / 2012^{+}$ \\
\hline North Greenland ${ }^{\ddagger}$ & - & - & $488^{+}$ & $184^{+}$ & $07 / 2012-12 / 2012^{+}$ \\
\hline
\end{tabular}

\footnotetext{
* This only constitutes a subset of the images that were investigated; many images were scrutinized without any ice islands being identified.

+ These values represent the contents of the database based on digitization that was completed through December 2012.

₹ Ice islands originating from these glaciers were not always monitored from the time of initial calving.
}

also represented in the database. These represent an additional $6.4 \pm 1.6,9.7 \pm 0.6$ and $7.7 \pm 0.5 \mathrm{~km}^{2}$ of calved ice associated with the 2008, 2010 and 2012 events, respectively. Three ice islands of $3.5 \pm 0.2,0.3 \pm 0.02$ and $0.55 \pm 0.03 \mathrm{~km}^{2}$ were also monitored after two previously unreported calving events that occurred in 2011.

The CI2D3 Database can be used to perform analyses of relevance to glaciology, oceanography and Arctic offshore engineering. Some preliminary results that illustrate the potential uses of the database are shown here. The database entries recorded at the time of publication that represent ice islands originating from the large 2010 Petermann Glacier calving event (the '2010 calving event') are used.

Estimates of the frequency and size distributions of glacial ice masses affect the probability of impact with offshore structures and the regional flux of fresh water into the ocean. Figure 3 shows the numbers of unique ice islands $>0.25 \mathrm{~km}^{2}$ that were observed in $14 \mathrm{~d}$ bins for the 2010 dataset $(n=1493)$. The total number of all ice islands peaked in the first half of 2011, then fell during the summer of 2011 and was relatively constant from the

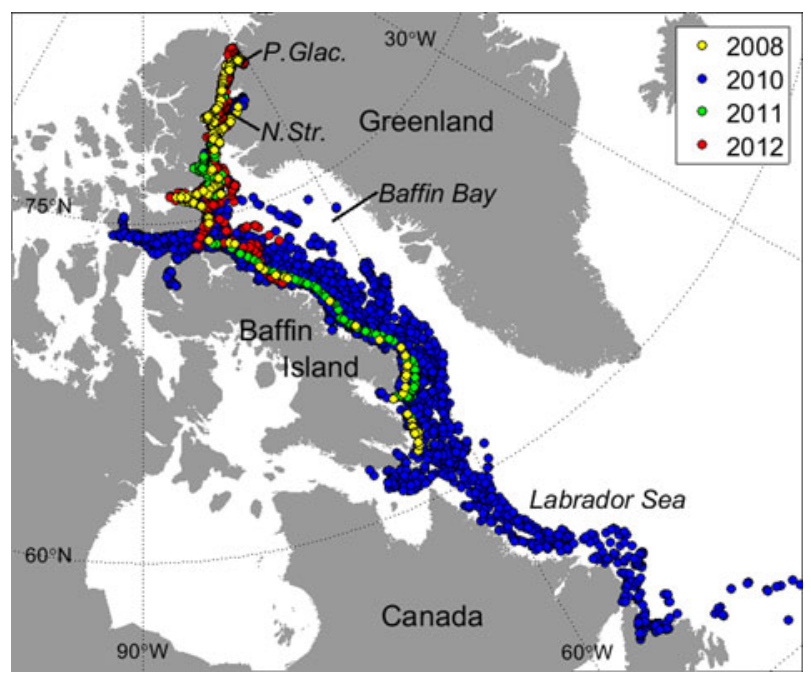

Fig. 2. Map showing the location of all Petermann Ice Islands represented in the Canadian Ice Island Drift, Deterioration and Detection Database. Colors denote the year of the corresponding Petermann Glacier calving event. 'P.Glac.', and 'N.Str.' identify Petermann Glacier and Nares Strait, respectively. autumn of 2011 until the end of current data collection. Small $\left(0.2-1 \mathrm{~km}^{2}\right)$ ice islands account for most of the numbers during the 2011 peak. The numbers of very large pieces ( $>4 \mathrm{~km}$ in length) dropped slowly over the 2-year observation period. Tournadre and others (2016) also report that the majority $(77 \%)$ of tabular icebergs detected in the Antarctic fall within the smallest size class $\left(<1 \mathrm{~km}^{2}\right.$ in surface extent), though the larger icebergs are important vectors of fresh water as they can persist for years and travel far from their original calving location.

Relationships between length and width (in this case calculated as the measured surface area divided by the maximum waterline length) may also be of interest for estimating surface area and mass. When the ice islands were large, the length-to-width relationship was quite consistent and the mean length-to-width ratio (L/W) for all 2010 calving event features was 2.95. The mean and Std dev. for features $>4 \mathrm{~km}$ in length were 2.95 and 0.58 . For features $<4 \mathrm{~km}$ in length, the mean was identical at 2.95, but the Std dev. was much larger at 1.08. These results fall outside the range of previously reported $\mathrm{L} / \mathrm{W}$ values. Jeffries and others (1987) data for ice islands $>200 \mathrm{~m}$ in length in the Arctic Ocean showed a mean L/W of $\sim 2.2$. Orheim (1980) found the average L/W for similar size Antarctic icebergs to be 1.6, while Hotzel and Miller (1983) showed L/ $W$ for icebergs off the East Coast of Canada to average $\sim 1.25$. We believe these differences are associated with ice fracture and are presently conducting modeling studies to develop a better understanding of fracture processes.

The nature of the southerly drift of the ice islands also showed interesting characteristics. Figure 4 shows the southward migration of all ice islands originating from the 2010 calving event from the time of calving (July 2010) until the summer of 2012. The bulk of the ice islands showed broadly similar southward migration rates, but the effects of grounding are evident. Ice islands that showed no southward movement for the extended period of time were grounded on the seabed. A range of ice island sizes were observed to ground along the coast of Baffin Island between $65^{\circ} \mathrm{N}$ and $75^{\circ} \mathrm{N}$. One example is PII-B, a $59 \mathrm{~km}^{2}$ descendant of the 2010 Petermann Ice Island that was grounded on the continental shelf off Baffin Island for $\sim 1.5$ years (Crawford and others, 2016).

One result of grounding (and in some instances drift into adjacent sounds and inlets such as Lancaster Sound) is that the pulse of ice features into southern latitudes was spread 


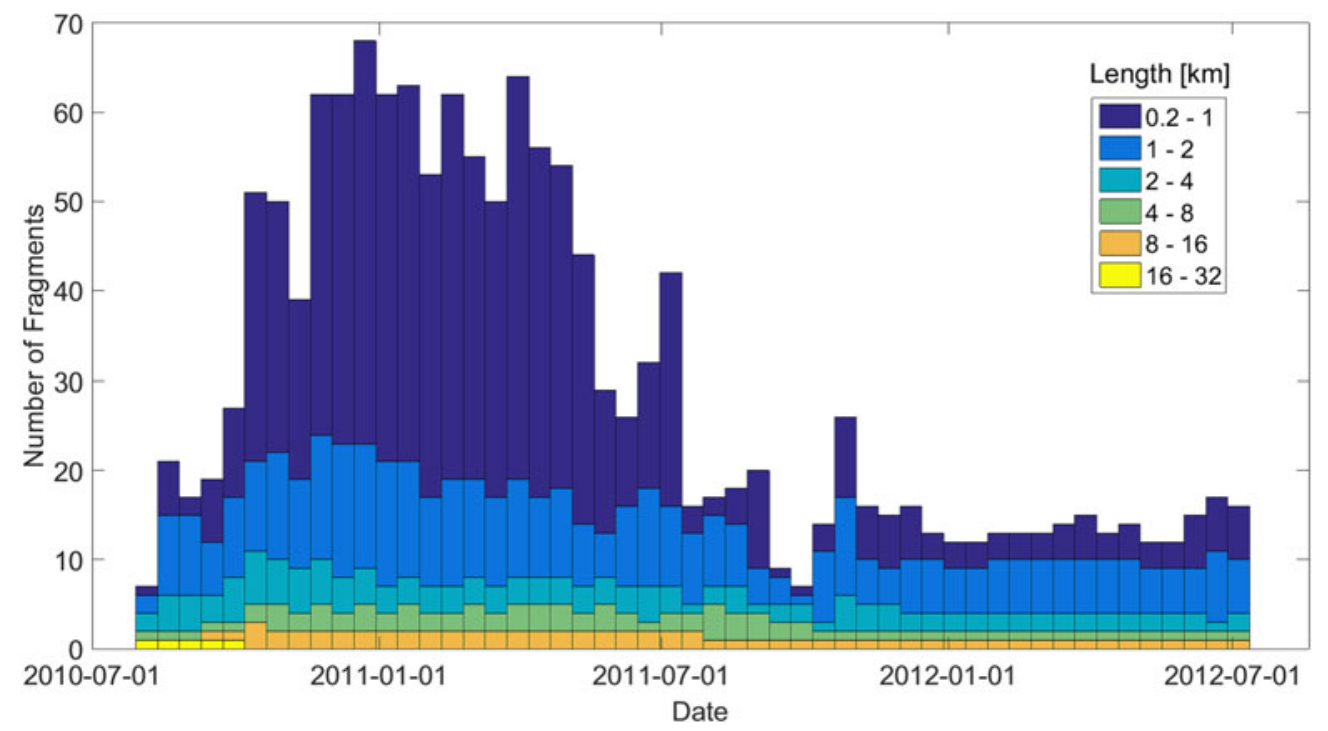

Fig. 3. The numbers of unique ice islands observed in 2-week time bins from the 2010 dataset. Note that the length categories are not uniform.

over a longer time period. The dashed line in Figure 4 shows an approximate extreme upper limit of southward movement, which was $\sim 40^{\circ}$ of latitude per year $\left(\sim 12 \mathrm{~km} \mathrm{~d}^{-1}\right)$. The mean drift speed of all ice islands originating from the 2010 calving event for which successive positions could be identified was $8.1 \mathrm{~km} \mathrm{~d}^{-1}$.

\section{CONCLUSIONS AND AVAILABILITY}

The CI2D3 Database represents a uniquely comprehensive set of north Greenland ice island observations. Its most notable and unique characteristic is the establishment of a lineage connecting all monitored ice islands down to 0.25 $\mathrm{km}^{2}$. Accurate, quality-controlled areal extents of the initial ice islands that were generated after recent Petermann Glacier calving events are reported with error magnitudes calculated from project-specific error assessments. Previously undocumented ice islands are also represented in the Cl2D3 Database, including three which calved from the Petermann Glacier in 2011 and >100 ice islands from the Steensby, Ryder and C.H. Ostenfeld glaciers.

The information contained within the CI2D3 Database will allow for novel drift and deterioration analyses, such as those showcased in Section 4. The database can also contribute to improving the operational modeling of these processes. The lineage component is used in a forthcoming study that will focus on the fracturing deterioration mechanism and the magnitude and dispersal of fresh water resulting from ice island drift and deterioration. Along with the drift and deterioration studies, the database can also be utilized to analyze the backscatter characteristics of ice islands using the CIS archived SAR imagery. Such detection analyses are important for developing and validating automated detection algorithms.

The Cl2D3 Database will be publically available during summer 2018 under record number 12678 in the PDC (https://www.polardata.ca/pdcsearch/PDCSearch.jsp? doi_id=12678). Until that time, a sample dataset is available on the project website (https://wirl.carleton.ca/ci2d3/).

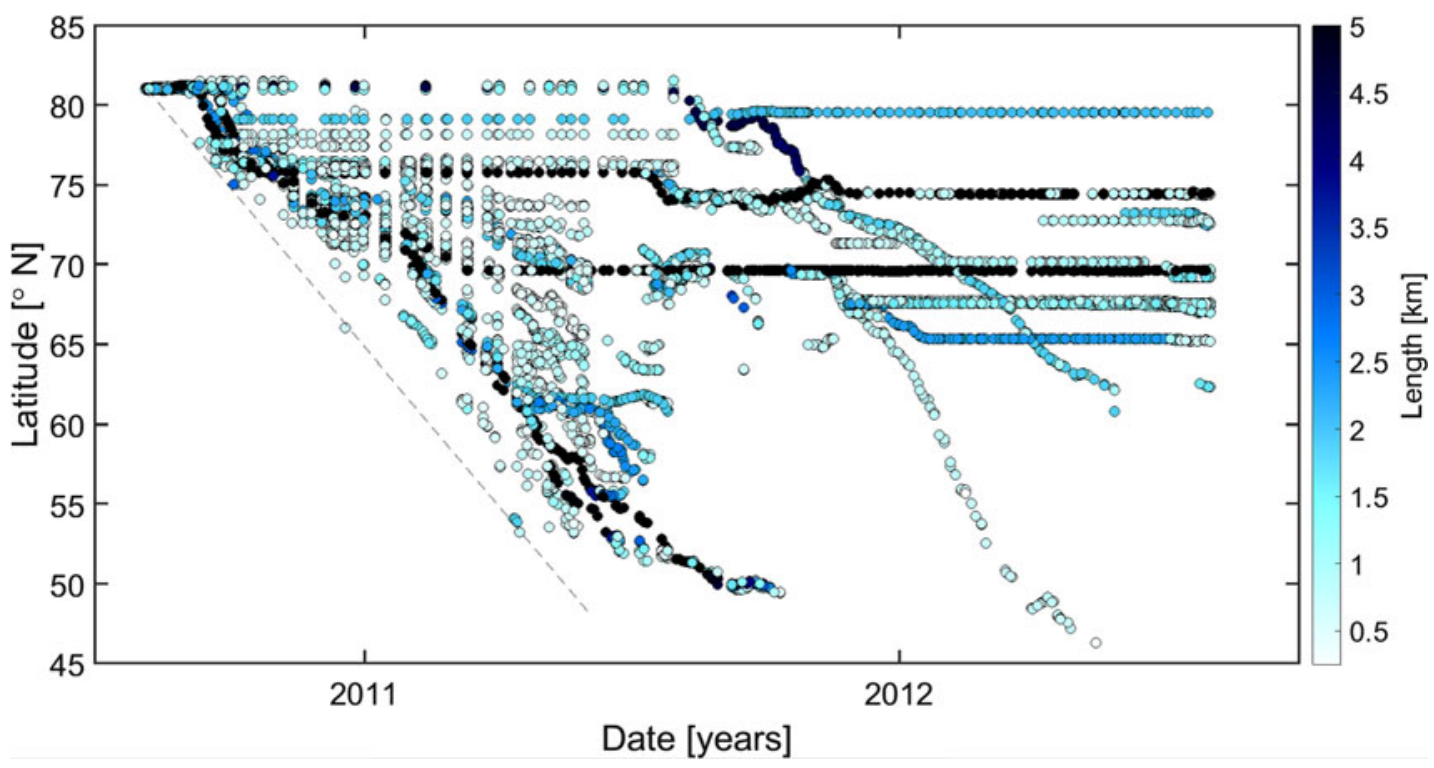

Fig. 4. Time series of latitude change for ice islands originating from the 2010 Petermann Glacier calving event. The color bar gives length scale (all pieces with length $>5 \mathrm{~km}$ are shown in black). The dashed line shows an approximate maximum southward drift rate of $12 \mathrm{~km} \mathrm{~d} \mathrm{~d}^{-1}$. 


\section{SUPPLEMENTARY MATERIAL}

The supplementary material for this article can be found at https://doi.org/10.1017/jog.2018.36

\section{ACKNOWLEDGEMENTS}

This project was undertaken with the financial support of the Government of Canada through Environment and Climate Change Canada and through the Polar Knowledge Canada project 'Safe Passage'. Funding from the Canadian Foundation for Innovation and the Ontario Research Fund supported the purchase of computer equipment. RADARSAT-1 and -2 data were supplied by the Canadian Ice Service through a Joint Project Agreement. Cl2D3 Database technicians Jeff Shepherd and Correy Schaad are thanked for their contributions to the database generation. Two groups of undergraduate students from Carleton University's GEOM 4008 and 4009 courses, instructed by Dan Patterson, developed customized ArcGIS tools for use during the Cl2D3 Database generation. Group members included Adam Garbo, Sonya Haskell, Sara Mannseichner, Marisa Ramey, Cameron Samson, Diandra Buttazzoni, Ryder Burt, Erik Duncan, Malek Singer and Emma Zerr. Gregory Lewis-Paley and Sougal Bouh Ali assisted greatly in setting up the PostgreSQL database.

\author{
${ }^{1}$ Water and Ice Research Lab, \\ Department of Geography and \\ Environmental Studies, Carleton \\ ANNA CRAWFORD ${ }^{1}$ \\ GREGORY CROCKER ${ }^{1,2}$ \\ DEREK MUELLER ${ }^{1}$ \\ University, B349 Loeb Building, 1125 LUC DESJARDINS ${ }^{1,3}$ \\ Colonel By Drive, Ottawa, Ontario, \\ K1S 5B6, Canada \\ ${ }^{2}$ Ballicater Consulting Ltd. Kingston, \\ RON SAPER ${ }^{1}$ \\ Ontario, K7L 4B4, Canada \\ ${ }^{3}$ Canadian Ice Service, Environment \\ and Climate Change Canada, 373 \\ Sussex Drive, Ottawa, Ontario, K1N \\ 7B1, Canada (retired) \\ E-mail: Anna Crawford <anna.crawford@carleton.ca>
}

\section{REFERENCES}

CIS (Canadian Ice Service) (2005) Manual of standard procedures for observing and reporting ice conditions. Canadian Ice Service, Environment and Climate Change Canada, Ottawa.
Crawford A and 7 others (2016) Journey of an Arctic ice island. Oceanography 29(2) (doi: 10.5670/oceanog.2016.30)

De Abreu R and 6 others (2011) RADARSAT-2 mode selection for maritime surveillance. External Client Report Defence Research and Development Canada, Ottawa.

Halliday EJ, King T, Bobby P, Copland L and Mueller DR (2012) Petermann Ice Island ' $A$ ' survey results, offshore Labrador. Houston, Texas, OTC 23714

Hotzel S and Miller J 1983. Icebergs: their physical dimensions and the presentation and application of measured data. Ann. Glaciol. 4

Jeffries MO, Sackinger WM and Shoemaker HD (1987) Geometry and physical properties of ice islands. Ninth International Conference on Port and Ocean Engineering Under Arctic Conditions, 1, 69-83

Johannessen OM, Babiker M and Miles MW (2011) Petermann Glacier, North Greenland: massive calving in 2010 and the past half century. Cryosphere Discuss. 5, 169-181 (doi: 10.5194/tcd-5-169-2011)

Lewis-Paley G (2015) Ice island variability in polarimetric Synthetic Aperture Radar: An exploratory analysis to improve detection and ice classification. (MSc thesis, Carleton University, Ottawa) https:// curve.carleton.ca/7530246d-884c-4fe7-818c-cb278387acb3

Marson J, Myers P, Hu X and Le Sommer J (2018) Using verticallyintegrated ocean fields to characterize Greenland icebergs' distribution and lifetime. Geophysical Research Letters. In press.

Münchow A, Padman L and Fricker HA (2014) Interannual changes of the floating ice shelf of Petermann Gletscher, North Greenland, from 2000 to 2012. J. Glaciol. 60(221), 489-499 (doi: 10.3189/2014JoG13J135)

Newell JP (1993) Exceptionally large icebergs and ice islands in eastern Canadian waters: a review of sightings from 1900 to present. Arctic 46(3), 205-211

Orheim O (1980) Physical characteristics and life expectancy of tabular Antarctic icebergs. Ann. Glaciol. 1, 11-18

Paul F and 19 others (2013) On the accuracy of glacier outlines derived from remote-sensing data. Ann. Glaciol. 54(63), 171182 (doi: 10.3189/2013AoG63A296)

Smith KL, Sherman AD, Shaw TJ and Sprintall J (2013) Icebergs as unique Lagrangian ecosystems in polar seas. Ann. Rev. Mar. Sci. 5(1), 269-287 (doi: 10.1146/annurev-marine-121211172317)

Stern AA and 10 others (2015) Wind-driven upwelling around grounded tabular icebergs. J. Geophys. Res. Oceans 120(8), 5820-5835 (doi: 10.1002/2015JC010805)

Tournadre J, Bouhier N, Girard-Ardhuin F and Rémy F (2016) Antarctic icebergs distributions 1992-2014. J. Geophys. Res. Oceans 121(1), 327-349 (doi: 10.1002/2015JC011178)

Vernet $M$ and 12 others (2012) Islands of ice: influence of free-drifting Antarctic icebergs on pelagic marine ecosystems. Oceanography 25(3), 38-39. (doi: 10.5670/oceanog.2012.72) 